\title{
PALHA DE SOJA (Glycine max) COMO SUBSTITUTO PARCIAL DA SILAGEM DE SORGO FORRAGEIRO (Sorghum bicolor ( L.) Moench) NA ALIMENTAÇÃO DE TERNEIROS DE CORTE CONFINADOS
}

\author{
SOYBEAN STRAW (Glycine max) AS A PARTIAL SUBSTITUTE OF SORGHUM SILAGE \\ (Sorghum bicolor (L.) Moench) IN THE FEEDING OF CONFINED CALVES
}

\author{
João Restle ${ }^{1}$ Dari Celestino Alves Filho ${ }^{2}$ Ivan Luiz Brondani ${ }^{3}$ \\ Jorge Luis Carvalho Flores ${ }^{4}$
}

\section{RESUMO}

O experimento teve como objetivo avaliar a utilização da palha de soja como substituto parcial da silagem de sorgo forrageiro na fração volumosa da dieta de terneiros confinados, sendo testados os seguintes tratamentos: T0 constituído por $100 \%$ de silagem de sorgo; T33 constituído por 66,67\% de silagem de sorgo, mais 33,33\% de feno de palha de soja; T66 constituído por $33,33 \%$ de silagem de sorgo, mais $66,67 \%$ de feno de palha de soja. As dietas foram fornecidas durante 77 dias para terneiros cruzas Charolês-Nelore com peso e idade média inicial de $165,6 \mathrm{~kg}$ e $11 \mathrm{meses,}$ respectivamente. A dieta alimentar foi isonitrogenada com $14 \%$ de proteína bruta $(P B)$ na matéria seca (MS), sendo $20 \%$ suprida na forma de uréia. A relação volumoso:concentrado com base na MS, foi de 70:30. Os dados foram submetidos à análise de regressão sendo obtidas as seguintes equações de regressão: para ganho de peso médio diário em $\mathrm{kg}$ $(G M D)=1,166273-0,00186 \mathrm{PI}$ (peso inicial) - 0,00351 NS (nível de substituição); consumo médio diário de $\mathrm{MS}$ em $\mathrm{kg} / 100$ $\mathrm{kg}$ peso vivo/dia $(\mathrm{CMSPPV})=2,284983+0,002679 \mathrm{PI}-$ 0,002303 NS; consumo médio diário de energia digestível Mcal/100kg peso vivo/dia $(C E D P P V)=5,709589+0,010964 P I$ - 0,018736 NS; conversão alimentar $(C A)=-4,426857+$ 0,064579 PI +0,023165 NS. Verificou-se que a cada aumento de $1 \%$ na substituição da silagem de sorgo por feno de palha de soja, ocorreu um decréscimo de $3,51 \mathrm{~g}$ no GMD e 2,3g no $C M S P P V$, enquanto que a conversão alimentar piorou em 0,023 unidades. $O$ aumento na proporção de palha de soja na dieta em substituição à silagem de sorgo resultou em um decréscimo linear no desempenho dos animais. No entanto, mesmo no maior nível de substituição, o ganho de peso médio diário foi satisfatório.

Palavras-chave: consumo voluntário, conversão alimentar, ganho de peso, palha, resíduo de cultura.
SUMMARY

The objective of the experiment was to evaluate the use of soybean straw as partial substitute for sorghum silage in the roughage fraction of the diet of confined calves, being tested the following treatments: T0 with 100\% of sorghum silage; T33 with $66.67 \%$ of sorghum silage plus $33.33 \%$ of soybean straw; T66 with $33.33 \%$ of sorghum silage plus $66.67 \%$ of soybean straw. The diets were fed during 77 days for Charolais-Nellore crossbred calves with an initial average weight and age of 165.6 $\mathrm{kg}$ and 11 months, respectively. The diets contained $14 \%$ of crude protein in the dry matter (DM), with $20 \%$ supplied in the form of urea. The roughage:concentrate ratio was of 70:30 (DM basis). The data were submitted to regression analysis, being obtained the following regression equations: for average daily gain in $\mathrm{kg}$ $(A D G)=1.166273-.00186 \mathrm{IW}$ (initial weigh) $-.00351 \mathrm{SL}$ (substitution level); daily dry matter intake in $\mathrm{kg} / 100 \mathrm{~kg}$ live weigh $($ DMILW $)=2.284983+.002679 \mathrm{IW}-.002303 \mathrm{SL}$; daily digestible energy intake Mcal/100 $\mathrm{kg}$ live weigh/day $(D E I L W)=$ $5.709589+.010964 \mathrm{IW}-.018736 \mathrm{SL} ;$ food convertion $(F C)=-$ $4.426857+.064579 \mathrm{IW}+.023165$ SL. It was verified that for each increase of $1 \%$ in the substitution of the sorghum silage by soybean straw, occured a decline of $3.51 \mathrm{~g}$ in $A D G, 2.3 \mathrm{~g}$ in DMILW, while food convertion worsen .023 units. The increase of the proportion of soybean straw in the diet in substitution to sorghum silage causes a linear decline in animal performance. However, even in the highest substitution level, weight gain is still satisfactory.

Key words: feed intake, food convertion, weight gain, straw, crop residue.

\footnotetext{
${ }^{1}$ Engenheiro Agrônomo, PhD., Professor Titular, Departamento de Zootecnia, Universidade Federal de Santa Maria (UFSM), Pesquisador CNPq, 97105-900, Santa Maria, RS. E-mail: restle@infoway.com.br. Autor para correspondência.

${ }^{2}$ Engenheiro Agrônomo, MSc., Professor, Departamento de Zootecnia, UFSM.

${ }^{3}$ Zootecnista, MSc., Professor, Departamento de Zootecnia, UFSM.

${ }^{4}$ Zootecnista, MSc.
} 


\section{INTRODUÇÃO}

A cultura da soja tem uma importância muito grande na economia do país, pois o farelo de soja é utilizado como principal fonte protéica nas rações animais no nosso meio. Além disso, grão e farelo são componentes importantes da entrada de divisas para o país em função da sua exportação. A produção média nacional de soja grão nos últimos nove anos foi de 21.621.686ton, sendo o Rio Grande do Sul responsável por $24,15 \%$ desse total (AGRIANUAL, 1997).

Conforme citado por CARVALHO (1992), a relação de palhada com o peso do grão varia de 120 a $150 \%$, mostrando que anualmente ficam nas lavouras no mínimo 6.265.964ton de palha de soja só no Rio Grande do Sul. Parte dessa palha poderia ser utilizada na alimentação de bovinos de corte durante o inverno, contribuindo para diminuir as perdas de peso ou mesmo proporcionar ganho de peso aos animais. No Brasil a maior parte das palhas produzidas após a colheita de grãos ou sementes são desperdiçadas, sendo pequeno o seu uso na alimentação dos animais. Segundo ANDERSON (1978), nos EUA, as palhas participam com 25 a $50 \%$ das rações fornecidas aos animais nos meses de inverno, sendo utilizadas tanto na forma exclusiva, misturada a concentrados ou consumidas diretamente pelos animais no campo.

As palhas se caracterizam pela abundância e baixo custo relativo, porém apresentam baixo valor nutritivo, com teores de proteína, energia e minerais baixos. Além disso, possuem altos teores de fibra devido aos carboidratos estruturais e fração indigerível alta (MARTIN, 1987; NUCCI, 1994). A utilização exclusiva de palha de soja na alimentação de novilhos resulta em perdas de peso (BAGLEY $\boldsymbol{e} t$ al., 1989), embora inferiores às perdas verificadas nos animais mantidos exclusivamente em campo nativo durante o inverno (MÜLLER et al., 1979).

As palhas podem ser associadas a outros volumosos de melhor qualidade e utilizadas na alimentação de bovinos, com bons resultados. RESTLE $\boldsymbol{e}$ t al. (dados não publicados) utilizaram a palha de trevo vesiculoso como substituto parcial da silagem de milho para novilhos confinados na fase de terminação. Os autores verificaram que, apesar da inclusão da palha causar uma redução no ganho de peso dos animais, esse foi próximo a um quilograma por animal/dia, mesmo no nível de substituição mais elevado, que foi de $75 \%$.

Apesar do grande volume de palha de soja produzida, poucas são as informações geradas no nosso meio sobre os resultados da sua utilização na alimentação de bovinos. O objetivo deste experi- mento foi de avaliar o potencial de utilização da palha de soja como substituto parcial da silagem de sorgo forrageiro na alimentação de terneiros, através do seu desempenho em confinamento.

\section{MATERIAL E MÉTODOS}

O experimento foi conduzido de setembro a dezembro de 1993, no Setor de Gado de Corte do Departamento de Zootecnia da Universidade Federal de Santa Maria, RS. Foram comparados os seguintes níveis de substituição da silagem de sorgo forrageiro (Agroceres - AG 2002 ${ }^{1}$ ) por feno de palha de soja triturada: T0 constituído por $100 \%$ de silagem de sorgo, mais concentrado; T33 constituído por $66,67 \%$ de silagem de sorgo, mais $33,33 \%$ de feno de palha de soja, mais concentrado e T66 constituído por $33,33 \%$ de silagem de sorgo, mais $66,67 \%$ de feno de palha de soja, mais concentrado.

A palha de soja foi triturada com o objetivo de desestruturar, principalmente, os colmos, resultando em fragmentos inferiores a quatro centímetros. As dietas fornecidas eram isonitrogenadas com $14 \%$ de PB na MS, sendo $20 \%$ supridas na forma de uréia. A relação volumoso:concentrado com base na MS foi de 70:30. A fração concentrada nas três dietas foi composta por milho grão triturado, farelo de soja, uréia, farinha de osso e sal comum (Tabela 1). Os animais foram adaptados às dietas e manejo alimentar durante 19 dias, passando após para o período experimental que teve uma duração de 77 dias. As pesagens ocorreram no início e no final do período experimental, com pesagens intermediárias a cada 21 dias, e 14 dias no último período, sempre observando um jejum prévio de sólidos de 14 horas antes de cada pesagem.

Tabela 1 - Composição percentual da matéria seca da dieta oferecida durante o período experimental.

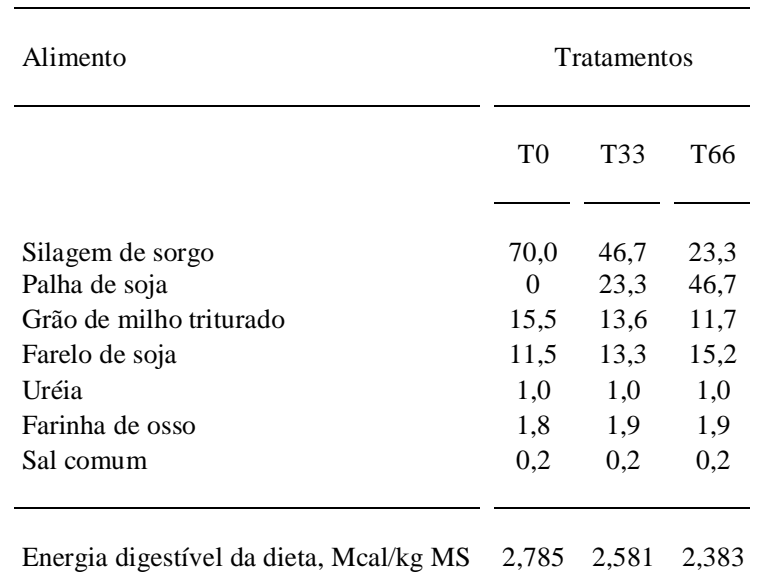


Utilizou-se um confinamento a céu aberto com seis piquetes, sendo cada um provido de um comedouro de madeira e um bebedouro de concreto, regulado por torneira automática. Os animais foram alimentados ad libitum duas vezes ao dia, sendo a metade da dieta fornecida às 8 horas e o restante às 16 horas. Diariamente, pela manhã, antes da alimentação, eram retiradas as sobras do dia anterior e pesadas para ajustes de consumo e posterior cálculo de consumo e conversão alimentar. A quantidade de matéria seca oferecida diariamente foi $10 \%$ superior ao consumo voluntário esperado.

Foram utilizados 18 terneiros cruzas Charolês-Nelore, com idade média inicial de 11 meses, e peso médio inicial de 165,6 $\pm 1,36 \mathrm{~kg}$, oriundos do Departamento de Zootecnia-UFSM. Os terneiros foram distribuídos aleatoriamente em seis lotes de três animais, sendo desverminados no início do período experimental, com um produto de largo espectro.

Antecedendo o período experimental, foram efetuadas as análises dos volumosos e ingredientes utilizados no concentrado, determinado-se a matéria seca e a proteína bruta. Durante o período experimental, a cada duas semanas eram coletadas e armazenadas em congelador, amostras de todos os constituintes da dieta para serem, posteriormente, analisadas. Foram determinados proteína bruta (PB), fibra em detergente neutro (FDN) e ácido (FDA), digestibilidade in vitro da matéria seca e matéria orgânica, sendo a energia digestível (ED) e o NDT estimados pela fórmula predita pelo ARC (1980).

O delineamento experimental foi o inteiramente casualizado, com duas repetições, cada uma com três animais. Os dados foram submetidos à análise de variância e de regressão através do programa estatístico SAS (1993), seguindo o modelo matemático: $Y_{i j l}=\mu+T_{i}+P I_{j}+e_{i j l}$, em que: $Y_{i j l}=$ variável dependente; $\mu=$ média geral; $T_{i}=$ efeito do tratamento de índice $\mathrm{i} ; P I_{j}=$ covariável peso inicial do lote de índice $\mathrm{j} ; e_{i j l}=$ erro aleatório associado a cada observação.

\section{RESULTADOS E DISCUSSÃO}

Na tabela 2, são apresentados os resultados da análise bromatológica dos alimentos constituintes da dieta. Observa-se que a palha de soja apresentou baixo valor protéico $(3,5 \%)$, sendo inferior aos $4,4 \%$ verificados por REHFELD \& BLASCZYK (1972) e os 4 a $6 \%$ obtidos por PEIXOTO et al. (1987). Os teores de FDN e FDA da palha de soja são superiores aos citados no NRC abela 2 - Matéria seca (MS), proteína bruta (PB), fibra em detergente neutro (FDN) e ácido (FDA), digestibilidade in vitro da matéria seca (MS) e da matéria orgânica (MO), nutrientes digestíveis totais (NDT) e energia digestível (ED) do feno de palha de soja, silagem de sorgo, milho grão moído e farelo de soja, utilizados para a elaboração das dietas.

\begin{tabular}{|c|c|c|c|c|c|c|c|c|}
\hline \multirow[t]{2}{*}{$\begin{array}{l}\text { Alimentos forne- } \\
\text { cidos }\end{array}$} & \multirow[t]{2}{*}{ MS } & \multirow[t]{2}{*}{ PB } & FDN & \multirow[t]{2}{*}{ FDA } & \multicolumn{2}{|c|}{$\begin{array}{l}\text { Dig. in } \\
\text { vitro, } \%\end{array}$} & \multirow[t]{2}{*}{$\begin{array}{l}\mathrm{NDT}^{*} \\
(\%)\end{array}$} & \multirow[t]{2}{*}{$\begin{array}{c}\text { ED } \\
\text { Mcal/kg MS }\end{array}$} \\
\hline & & & $\%)$ & & MS & $\mathrm{MO}$ & & \\
\hline Palha de Soja & 96,0 & 3,5 & 79,1 & 59,4 & 40,2 & 38,1 & 37,3 & 1,64 \\
\hline Silagem de sorgo & 28,9 & 6,4 & 61,5 & 43,7 & 58,1 & 57,0 & 56,4 & 2,48 \\
\hline Milho grão moído & 84,5 & 8,5 & - & - & 865 & 87,2 & 89,1 & 3,92 \\
\hline Farelo de soja & 85,2 & 47,0 & - & - & 88,8 & 88,7 & 86,3 & 3,79 \\
\hline
\end{tabular}

Estimado pelo ARC (1980).

(1984) e próximos aos relatados por CARVALHO (1992). A digestibilidade in vitro da matéria seca (DIVMS) obtida $(40,2 \%)$ foi inferior aos valores citados por PRATES \& LEBOUTE (1980), PIRES et al. (1981) e QUEIROZ et al. (1990) que foram de 43,$0 ; 42,5$ e $55,2 \%$, respectivamente. A concentração de energia digestível $(1,64 \mathrm{Mcal} / \mathrm{kg} \mathrm{MS})$ verificada na palha de soja foi inferior ao valor relatado pelo NRC (1984) 1,85Mcal/kg MS e o percentual de NDT de $37,3 \%$ foi próximo ao encontrado por PEIXOTO et al. (1987) que variou de 38 a $44 \%$.

Peso inicial, que foi utilizado como covariável, afetou o ganho de peso médio diário $(\mathrm{P}<0,045)$. O consumo de matéria seca (CMS) ajustado para $100 \mathrm{~kg}$ de peso vivo (CMSPPV) representado na Figura 1, mostra que houve apenas um pequeno decréscimo linear não significativo (P>0,1367) no CMSPPV de 2,3g/100 kg PV, para cada unidade percentual de substituição da silagem por palha de soja. As médias estimadas para consumo de matéria seca ajustado para peso vivo do animal foram de 2,75; 2,72 e 2,73kg MS/100kg PV/dia, para T0, T33 e T66, respectivamente. Ao expressar o consumo de matéria seca por unidade de tamanho metabólico, g/kg PV $\mathrm{PV}^{0,75}$ (UTM), verificou-se que com o aumento do teor de palha de soja na fração volumosa da dieta, houve pequena queda no consumo de matéria seca. Isso é mostrado pela equação de regressão: CMS em g/UTM = 0,065969 + 0,000220 PI - 0,000103 NS (P>0,0976; $\left.\mathrm{R}^{2}=0,87\right)$. Segundo CARVALHO et al. (1997), o consumo de todos os nutrientes é de extrema importância pois são eles que determinam o desempenho animal. Segundo MERTENS (1992), o consumo de alimento é regulado por vários fatores, como: animal (peso vivo, nível de produção, estado fisiológico, etc.), alimento 


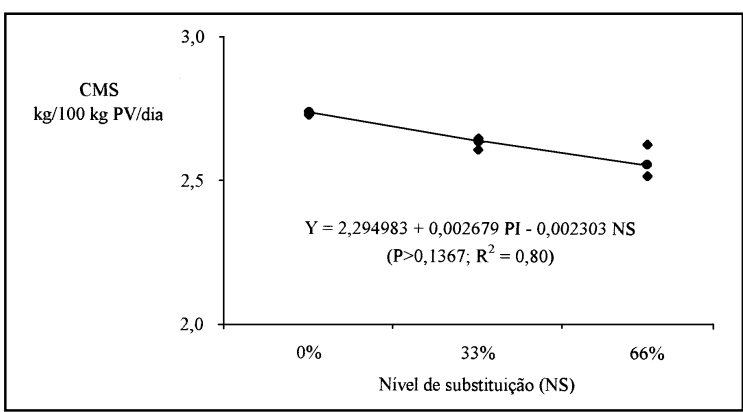

Figura 1 - Consumo médio diário de matéria seca (CMS) em $\mathrm{kg} / 100 \mathrm{~kg}$ PV, em função do nível de substituição de palha de soja na fração volumosa da dieta.

(fibra, demanda energética, volume, etc.) e condições de alimentação (disponibilidade de alimento, freqüência de alimentação, tempo de acesso ao alimento, etc.). Além disso, fatores ambientais ao qual o animal está exposto também podem afetar o consumo (NRC, 1996).

No presente experimento, o único fator que variou na alimentação foi o nível de palha de soja na fração volumosa da dieta. $\mathrm{O}$ que causou a diminuição no CMS, a medida que aumentou o nível de palha de soja, foi o elevado teor de fibra e a baixa digestibilidade da palha (Tabela 1). É através da taxa de digestão e da taxa de passagem dos alimentos que o conteúdo do rúmen é aliviado (VAN SOEST, 1982). Quanto mais rápido o conteúdo do rúmen é aliviado maior o consumo de matéria seca. MERTENS (1992) relata que em dietas com baixa densidade energética (teor de fibra elevado) em relação ao requerimento do animal, o consumo será limitado pelo efeito do enchimento do alimento.

Redução no CMS expresso em função do peso vivo dos animais também foi verificado no trabalho realizado por PACOLA et al. (1983), onde o CMS foi de 2,17; 2,05; 1,94 e 1,88kg MS/100kg $\mathrm{PV}$, quando o teor de palha de soja na fração volumosa da dieta aumentou para 70, 80, 90 e 100\%, respectivamente. RESTLE $\boldsymbol{e t}$ al. (dados não publicados) também traçaram equações para expressar o consumo ajustado para peso do animal, verificando que o aumento de $1 \%$ de palha de trevo vesiculoso na dieta provocou um decréscimo linear de $1,0 \mathrm{~g}$ de MS por $100 \mathrm{~kg}$ de PV e de 0,076g/UTM. Considerando a dieta total, CRUZ (1992) cita um consumo por animal por dia de $8,13 \mathrm{~kg}$ de MS com um teor de palha de soja de $15 \%$ e que caiu para $5,45 \mathrm{~kg}$ de MS/animal/dia quando o teor de palha de soja aumentou para $40 \%$. Segundo PRATES \& LEBOUTE (1980), a palha de soja utilizada como única fonte de volumoso para um novilho de $300 \mathrm{~kg}$ de peso não atingirá um consumo suficiente de matéria seca, proteína ou energia digestível para sua mantença.
O consumo diário de energia digestível por animal expresso pela equação $\mathrm{CED}=-0,596384$ + 0,093749 PI - 0,045204 NS mostra que, para cada unidade percentual de substituição da silagem por palha de soja, houve uma queda no CED de 0,045Mcal. Na figura 2, é apresentada a equação de regressão para consumo de energia digestível por $100 \mathrm{~kg}$ de $\mathrm{PV}$, onde se verifica que o CED/100kg PV decresceu em 0,018Mcal/dia para cada unidade percentual de substituição da silagem por palha de soja na fração volumosa da dieta. O CED por unidade de tamanho metabólico também foi afetado pelo nível de palha de soja na dieta, conforme a equação de regressão CED/UTM $=158,023+0,751$ PI 0,742 NS $\left(\mathrm{P}<0,0019 ; \mathrm{R}^{2}=0,98\right)$, onde se verifica que para cada unidade percentual de substituição da silagem por palha de soja na dieta o consumo decresceu em $0,742 \mathrm{Kcal} / \mathrm{kg} \mathrm{PV}{ }^{0,75}$. RESTLE et al. (dados não publicados) também verificaram que para cada unidade percentual de substituição da silagem por palha de trevo vesiculoso o CED em g/UTM e por $100 \mathrm{~kg}$ PV decresce em 0,0011 e 0,034Mcal/dia, respectivamente.

A queda no consumo de ED foi o resultado da pequena queda do CMS e, principalmente, da redução da concentração energética da dieta alimentar, à medida que aumentou a proporção de palha de soja em substituição à silagem de sorgo. A concentração de ED da palha de soja $(1,64 \mathrm{Mcal} / \mathrm{kg}$ $\mathrm{MS}$ ), foi bem inferior a da silagem de sorgo $(2,48 \mathrm{Mcal} / \mathrm{kg} \mathrm{MS})$ o que causou uma queda na concentração energética da dieta em 7,3 e 14,4\% no T33 e T66, respectivamente. Verificou-se que a queda no CMS por $100 \mathrm{~kg}$ PV caiu apenas em 1,1 e $0,7 \%$ no T33 e T66, ao passo que o CED por $100 \mathrm{~kg}$ PV caiu em 10,5 e 21,3\%, respectivamente. Portanto, fica claro que foi a queda da concentração energética da dieta a principal responsável pela queda do CED. Constatação contrária a do presente experimento foi feita por OSPINA \& PRATES (1998). Segundo esses autores, com animais de altas exigências nutri-

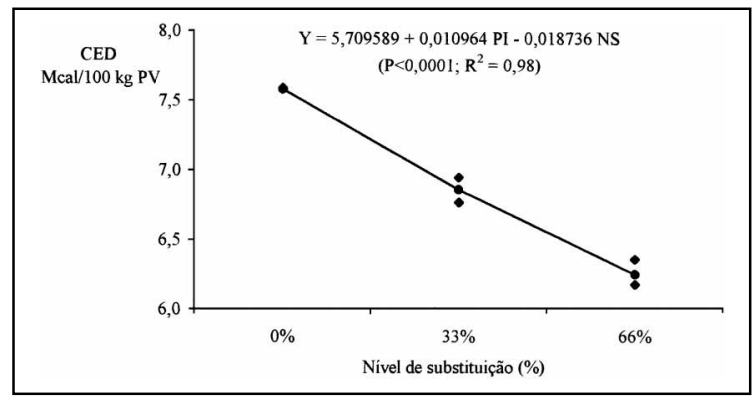

Figura 2 - Consumo de energia digestível (CED) por 100kg do peso vivo, em função do nível de substituição de palha de soja na fração volumosa da dieta. 
cionais, alimentados exclusivamente com fenos de qualidade média, os fatores relacionados ao consumo foram mais relevantes que os fatores relacionados à digestibilidade na determinação do consumo de nutrientes digestíveis totais.

O ganho de peso médio diário diferiu entre os tratamentos $(\mathrm{P}<0,0192)$, sendo as médias verificadas de 0,$848 ; 0,747$ e $0,623 \mathrm{~kg}$ para T0, T33 e T66, respectivamente. O GMD apresentou uma queda linear, à medida que a proporção de feno de palha de soja aumentou na dieta. Como se pode verificar na figura 3 , o GMD dos animais decresceu 3,51g para cada unidade percentual de substituição da silagem por palha de soja na fração volumosa da dieta. A queda no GMD foi uma consequiência da redução no consumo de ED. A queda no GMD foi de 12 e 26,5\%, respectivamente, para o T33 e T66, que acompanhou o decréscimo no consumo de ED que foi de 14,8 e $23,9 \%$, respectivamente. NUCCI (1994) também verificou queda semelhante no GMD que foi de $3,47 \mathrm{~g}$ para cada aumento de $1 \%$ de palha de trevo vesiculoso, como substituto da silagem de milho na fração volumosa da dieta.

Utilizando ponta de cana-de-açúcar mais palha de soja na engorda de novilhos em confinamento PACOLA et al. (1983) também verificaram que o GMD decresceu $(0,611,0,459,0,321$ e $0,098 \mathrm{~kg}$ ) com o aumento de palha de soja $(70,80,90$ e $100 \%$ ) na fração volumosa da dieta. Segundo CRUZ (1992), utilizando diferentes restos de cultura ou palhas para novilhos em crescimento (peso inicial $253 \mathrm{~kg}$ ), o GMD também decresceu com o aumento de palha de soja na dieta, sendo de $1,32 \mathrm{~kg}$ quando a proporção de palha foi de $15 \%, 0,97 \mathrm{~kg}$ com $20 \%$ de palha, caindo para $0,91 \mathrm{~kg}$ quando a proporção foi de $40 \%$ de MS de palha de soja na dieta total.

O GMD verificado para o T0 foi similar ao relatado por RESTLE et al. (1998), obtido com terneiros em condições de pastagem cultivada de inverno e que foi de $0,847 \mathrm{~kg}$. Já o GMD apresentado

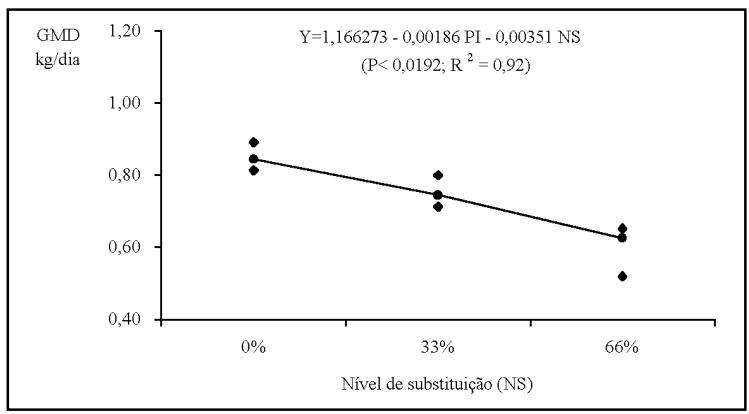

Figura 3 - Ganho médio diário (GMD), em função do nível de substituição da palha de soja na fração volumosa da dieta. pelos animais do T66 foi levemente superior ao obtido por RESTLE $\boldsymbol{e t}$ al. (1992). Os autores trabalharam com terneiros desmamados aos 90 dias, alimentados com $60 \%$ da fração volumoso com feno de palha de trevo vesiculoso e $40 \%$ com silagem de sorgo forrageiro, e obtiveram um GMD de $0,505 \mathrm{~kg} / \mathrm{animal} / \mathrm{dia}$.

A conversão de matéria seca consumida em ganho de peso foi afetada $(\mathrm{P}<0,0482)$ pelo nível de palha de soja na fração volumosa da dieta, conforme pode ser verificado na figura 4 . A conversão alimentar piorou 0,023 para cada unidade percentual de substituição da silagem por palha de soja na fração volumosa da dieta. A queda na eficiência alimentar, à medida que aumentou o teor de palha, foi uma conseqüência da redução da concentração energética da dieta, o que causou uma redução do consumo de ED. No entanto, a eficiência na transformação de ED consumida em ganho de peso, não foi afetada $(\mathrm{P}>0,4075)$ pelo nível de palha na fração volumosa. Isso indica que, à medida que caiu o consumo de ED, também caiu o ganho de peso. NUCCI (1994), utilizando quatro níveis de substituição de silagem de milho por palha de trevo vesiculoso, também verificou que a conversão alimentar em novilhos na fase de terminação aumentou em 0,017 para cada $1 \%$ de incremento de palha na fração volumosa da dieta.

Embora o desempenho dos animais tenha decrescido com o aumento da palha de soja na dieta, o desempenho pode ser considerado satisfatório mesmo no nível mais elevado de substituição. Esses resultados mostram que a palha de soja, que é um resíduo abundante no nosso meio, é uma alternativa viável na alimentação de gado de corte.

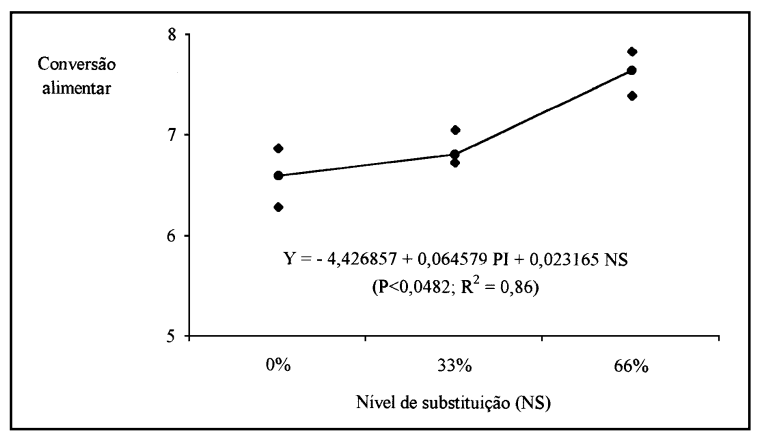

Figura 4 - Conversão alimentar, em função do nível de substituição de palha de soja na fração volumosa da dieta.

\section{CONCLUSÕES}

O aumento no nível de palha de soja na dieta de terneiros causa uma redução linear no con- 
sumo de energia digestível, no ganho de peso e na eficiência alimentar. No entanto, mesmo no nível mais elevado de substituição de silagem de sorgo forrageiro por palha de soja, o ganho de peso dos animais é satisfatório.

\section{AGRADECIMENTOS}

Ao Prof. PhD. José Henrique Souza da Silva pelo auxílio nas análises estatísticas.

\section{FONTES DE AQUISIÇÃO}

${ }^{1}$ Agroceres - AG 2002 - Escritórios Regionais Sul: Passo Fundo/RS Rua Independência, 893, Caixa postal 93, CEP: 99100 - 000, Tels.: (054) 312-2799, 312-2926.

\section{REFERÊNCIAS BIBLIOGRÁFICAS}

ANDERSON, D.C. Use of cereal residues in beef cattle productions systems. Journal of Animal Science, Champaign, v.46, n.3, p.849-861. 1978.

AGRIANUAL, Anuário estatístico da agricultura brasileira 97. São Paulo: Argos Comunicação, 1997. 435p.

A.R.C. Agricultural Research Council. The nutrient requirements of ruminant livestock. Surrey : The Gressham, 1980. 351p.

BAGLEY, C.P., MORRISON, D.G., FEAZEL, J.I., et. al. Influence of roughage on wintering beef heifer performance. Nutrition Reports International, v.39, n.3, p.575-585. 1989.

CARVALHO, F.C. de. Disponibilidade de resíduos agroindustriais e do beneficiamento de produtos agrícolas. In: SIMPÓSIO DE UTILIZAÇÃO DE SUBPRODUTOS AGROINDUSTRIAIS E RESÍDUOS DE COLHEITA NA ALIMENTAÇÃO DE RUMINANTES, 1992, São Carlos Anais... São Carlos : EMBRAPA, 1992. 349 p. P. 7-27.

CARVALHO, A.Ú., FILHO VALADARES, S. de C., SILVA, J.F.C. da, et al. Níveis de concentrado em dietas de zebuínos. 1. Consumo e Digestibilidade Aparente. Revista da Sociedade Brasileira de Zootecnia, v.26, n.5, p.986-995, 1997

CRUZ, G.M. da. Utilização dos restos de culturas e palhas na alimentação de ruminantes. In: SIMPÓSIO DE UTILIZAÇÃO DE SUBPRODUTOS AGROINDUSTRIAIS E RESÍDUOS DE COLHEITA NA ALIMENTAÇÃO DE RUMINANTES, 1992, São Carlos. Anais... São Carlos : EMBRAPA, 1992. 349p. 99-121.

MARTIN, L.C.T. Confinamento de bovinos de corte. Modernas técnicas. 2 ed. São Paulo : Livraria Nobel, 1987. 124p.

MERTENS, D.R. Análise da fibra e sua utilização na avaliação de alimentos e formulação de rações. In: SIMPÓSIO INTERNAIONAL DE RUMINANTES, REUNIÃO ANUAL SOCIEDADE BRASILEIRA DE ZOOTECNIA, 29, 1992, Lavras, MG. Anais... Lavras : Sociedade Brasileira de Zootecnia, 1992. 381p. p.188-219.

MULLER, I., RESTLE, J., STILES, D.A. Utilization of agriculture residues. I supplementation of soybean straw for growing beef calves. Journal of Animal Science, Champaign, v.49, n.1, p.269, 1979

NRC, National Reaserach Council. Nutrient Requerements of beef cattle. 6 ed. Washington, D.C. : National Academy, 1984. 90p.

NRC, National Research Council. Nutrient Requerements of beef cattle. $7^{\text {th }}$ revised edition. Washington : National Academy, 1996. 404p.

NUCCI, E.P.D. Substituição parcial de silagem de milho por palha de trevo vesiculoso (Trifolium vesiculosum Savi cv. "Iuchi") no desempenho de novilhos da raça Charolês em confinamento. Santa Maria, RS, 1994. 61 p. Dissertação (Mestrado em Zootecnia) - Curso de Pós-graduação em Zootecnia, Universidade Federal de Santa Maria, 1994.

OSPINA, H., PRATES, Ê.R. Efeito de quatro níveis de oferta de feno sobre o consumo de nutrientes digestíveis por bezerros. Revista da Sociedade Brasileira de Zootecnia, Viçosa, v.27, n.4, p.809-814, 1998.

PACOLA, L.J., CAIElli, E.L., MATTOS, J.C.A. de. Ponta de cana-de-açúcar queimada mais palha de soja na engorda de bovinos confinados. Boletim da Industria Animal, Nova Odessa, v.40, n.2, p.195-199, jul./dez. 1983.

PEIXOTO, A.M., BOIN, C., HADDAD, C.M. et al. Confinamento de bovinos de corte. Piracicaba, SP. : FEALQ, 1987. p.51.

PIRES, M.B.G., TRINDADE, D.S., QUADROS, A.T.F Composição química e digestibilidade in vitro de palhas de soja, arroz, milho, aveia e trigo. In: REUNIÃO ANUAL SOCIEDADE BRASILEIRA DE ZOOTECNIA., 1981, Goiânia, GO. Anais... Goiânia : Sociedade Brasileira de Zootecnia, 1981.417p. p.322.

PRATES, E.R., LEBOUTE, E.M. Avaliação do valor nutritivo de resíduos de cultivos e de indústria. Revista da Sociedade Brasileira de Zootecnia, Viçosa, v.9, n.2, p.248-259, 1980.

QUEIROZ, C.I. de A., GONÇALVES, L.C., SILVA, H.M. Utilização de restos de culturas na engorda de bovinos leiteiros. In: REUNIÃO ANUAL SOCIEDADE BRASILEIRA DE ZOOTECNIA., 1990, Campinas, SP Anais... Campinas : Sociedade Brasileira de Zootecnia, 1990. 813 p. p.37.

REHFELD, O., BLASCZYK, G. Utilização da palha de arroz e da palha de soja como único volumoso para bezerros após a desmama. Pesquisa Agropecuária Brasileira, Série Zootécnica, n.7, p.13-15, 1972

RESTLE, J., ALMEIDA, S.R.S. de, OURIQUE, N.L. Comparação de diferentes tipos de fenos na alimentação de terneiros de corte. In: REUNIÃO ANUAL SOCIEDADE BRASILEIRA DE ZOOTECNIA, 1992, Lavras, MG. Anais... Lavras : Sociedade Brasileira Zootecnia, 1992. 576p. p.143.

RESTLE, J., LUPATINI, G.C., ROSO, C., et al. Eficiência e desempenho de categorias de bovinos de corte em pastagem cultivada. Revista da Sociedade Brasileira de Zootecnia, Viçosa, v.27, n.2, p.397-404, 1998.

SAS INSTITUTE. SAS/STAT User's Guide: Statistics, 4 Version 6. Cary, NC : SAS Inst, 1993. v.3.

VAN SOEST. Nutritional ecology of the ruminant. Corvallis : O \& Books, 1982. 374p. 